\title{
Nurses' perception of nursing services documentation barriers: a qualitative approach
}

\author{
Seyed Majid Vafaei ${ }^{1}$, Zahra Sadat Manzari ${ }^{2}$, Abbas Heydari ${ }^{3}$, Razieh Froutan ${ }^{4}$, Leila Amiri Farahani ${ }^{5}$
}

\begin{abstract}
Background: Researches has shown that the quality of nursing documentation services in the world, including Iran, is far from existing standards. Understanding the barriers to improving the documentation of nursing services is essential for the first step. The aim of this study was to identify barriers to improving the nursing documentation services using the experience of nurses in the emergency department of one of the Iranian hospitals. Materials and Methods: This study is based on content analysis in accordance with the style of Graneheim in 2017 in the emergency department of one of the Iranian hospitals. This qualitative study was performed on 20 participant from different nursing grades including 17 nurses, 1 head nurse, and 2 members of the accreditation committee. The data were collected through semi-structured interviews and using interview guide and field note. Results: Research data have been explained in four main themes of qualification of documentation including sub-categories of the need for effective training, the need for training in the standards of documentation, and the necessity of skills in reporting; job burnout including sub-categories of job stress and work pressure; perceived control including sub-categories of planned control and effective monitoring and control; intra-organizational coordination including sub-categories of improving health information system and documentation management time, legal barrier for documentation including sub-categories of escaping from the law and legal liabilities.

Conclusion: In this study, 599 primary codes were extracted and the main themes documentation competency, job burnout, perceived control, intraorganizational coordination, and legal barrier extracted.
\end{abstract}

Keywords: qualitative approach, barriers, nursing services documentation

\section{INTRODUCTION}

Documentation is an important factor in improving the quality of nursing care, and quality promotion is an effective factor in the transparency of nursing practice (1). Researches shows that the quality of documentation of patients' files is not satisfactory and is not in accordance with nursing standards (1-3). Several methods are used, such as workshop training, continuous and planned monitoring, the use of documentary evidence-based procedures, document service audits, and reduced work pressure to improve the documentation of nursing care (4-7). In Iran, this problem is more prominent than other developed countries in the world, which we are trying to improve the conditions and bring them closer to standards.

In this regard, many descriptive studies have been done on the documentation of nursing services, but these studies have not significantly improved. In the research environment, a preliminary study showed that the current documentation has many problems, and the researcher's observations, which have been present in this environment for many years, are in agreement with this issue. Introduction to intervention In this regard, understanding the experiences of nurses working in the research environment is a barrier to the documentation of nursing services so that effective interventions can be planned and, on the other hand, they also insure the participation of nurses. Accordingly, this study aims to identify

\footnotetext{
1 PhD candidate in Nursing, School of Nursing and Midwifery, Mashhad University of Medical Sciences, Mashhad. Iran. Email: vafaeim@mums.ac.ir

2 Assistant Professor, Medical-Surgical Nursing Department, Faculty of Nursing and Midwifery, Mashhad University of Medical Sciences, Mashhad, Iran.

3 Department of Medical- Surgical Nursing, School of Nursing and Midwifery, Mashhad University of Medical Sciences, Mashhad, Iran.

${ }^{4}$ Assistant Professor, Medical-Surgical Nursing Department, Faculty of Nursing and Midwifery, Mashhad University of Medical Sciences, Mashhad, Iran.

${ }_{5}$ Assistant professor Department of Reproductive Health and Midwifery, School of Nursing and Midwifery, Iran University of Medical Sciences, Tehran, Iran.
}

\section{Correspondence: Zahra Sadat Manzari}

Assistant Professor, Medical-Surgical Nursing Department, Faculty of Nursing and Midwifery, Mashhad University of Medical Sciences, Mashhad, Iran. Tel: +985138591511

E-mail:manzariz@mums.ac.ir

Received: 4 Jan 2018, Accepted: 13 Feb 2018

(C) 2018 by the authors; licensee Modestum Ltd., UK. This article is an open access article distributed under the terms and conditions of the Creative Commons Attribution License (http://creativecommons.org/licenses/by/4.0/). 
these barriers nurses' perception of nursing services documentation in the emergency department of one of the hospitals in Iran.

\section{RESEARCH METHOD}

Content analysis strategy has been used in this research. Participants were selected based on purpose from among the emergency department staff at one of the Iranian hospitals. It is a state-owned hospital covered by a medical university with 240 active beds. Participants working in the Emergency Department Hospital with diverse backgrounds and undergraduate nursing graduates were male and female. Accordingly, the researcher conducted 20 semi- structured interviews with 13 contributors. Terms of participation Participants in the research had at least one year of work experience in the emergency department and were involved in the process of documentation of nursing services. Sampling was initially based on the purpose and then on the development of the theory and data collection based on Snowball sampling. The data of this study was collected through semi-structured interviews with 20 persons involved in nursing documentation, which had at least one year of work experience and 20 hours of observation.

Data collection was started from clinical nurses and then extended to other groups according to the extracted data and codes. This qualitative study was performed on 20 participant from different nursing grades including 17 nurses, 1 head nurse, and 2 members of the accreditation committee nurses, 2 medical doctor and one matron. The interview guide included several open questions to allow participants to express their perceptions and experiences in detail. The length of the interview varied from 65 minutes to 30 minutes to 90 minutes depending on the participants' circumstances. At the beginning of each interview, participants were asked to describe their work day. They were then asked to describe their perceptions and practices regarding how to document nursing care. After each interview, the recorded information was examined and then the interviews were transcribed word by word. The recorded information was typed and rematched with the recordings; this action was taken to increase the accuracy of the information recorded and to allow researchers to gain more control over the information provided. Therefore, based on this, the following were removed, respectively, by the implementation of the word-for-word interview bar immediately after each interview, by reading the entire text several times to obtain a general understanding of the content, the division of the text into meaning, Extracting a summary of semantic and coding units, classifying primary codes into subcategories and hands based on comparing their similarities and differences, and finally extracting categories as the expression of latent content in the data that results from Each unstructured interview was the guide for the next interview, so sampling continued until saturation. The research question was: What are the barriers and problems associated with documentation with regard to the experiences of nursing staff in the emergency department?

The validity and reliability of the present study are rooted in four dimensions of credibility, Dependability, conformability, and transferability (8). Credibility of this research was obtained through continuous engagement to the participants and the research data, and the correctional views of the experts in the process of interviews and the analysis of the extracted Credibility d data were used. In addition, the text of interviews, extracted codes, and subcategories were shared with some contributors. Integration was used in the data collection method and attempts have been made to select the a variety of samples so that staff from different groups depending on the type of responsibility, use of the opinion of experts outside the research team to evaluate the coordination of the findings, interpret and conclusions based on data could be provided. In the case of conformability, all the activities carried out, including the stages of the work and how the data were obtained, were carefully recorded. Finally, for transferability of the research findings, efforts were made to share the information obtained with an individual outside the research environment where the situations was similar to the participants in the research, and the results would be matched with his experiences. In this research, the purpose of the research is to explain the interview method. This study has been approved by the University's Ethics Committee of Mashhad University Health Sciences under the code 940864. To respect ethics in the research, consent has been obtained from all the participants and the confidentiality of their views has been guaranteed. The initial code number was 599, which decreased to 11 subcategory and finally to 5 category.

\section{FINDINGS}

In this study were employees of the emergency department whose characteristics are described in Table 1. The average age, work experience of the participants was 32.5 and 8.3 years, and all nurses are MSN and others were an emergency medicine and matron has master's psychology and two General practitioner. Research data have been 
Table 1: Categories and sub-categories resulting from analysis of interviews

1. Documentation competency

1.1 Necessity of effective training

1.2 Need to train documentation standards

1.3 Need to increase skills in reporting

4. Intra-organizational coordination

4.1 Improvement of health information system

2. Job burnout

4.2 Documentation time management

2.1 Job stress

2.2 Work pressure

5. Legal barrier to documentation

5.1 escaping from the law

3. Perceived control

5.2 Legal liabilities

3.1 Planned control

3.2 Effective contro

described in four main categories of documentation competency, job burnout, perceived control, intra-organizational coordination, and legal barrier of documentation, which are described in more detail below with examples of interviews.

\section{DOCUMENTATION COMPETENCY}

In this study, this main theme, the need for effective training, the need for training of the documentation standards and the Need to increase skills in reporting .

Participants' experiences regarding the need for effective training indicated that the training of emergency department staff was not structured and targeted, but the main trend in the learning process is through trial and learning from experienced people. Nurses' experiences in the development of knowledge in the emergency department indicate that the research environment has not predicted the process of systematic need measurement, and in-service experience has a key role in the quality of documentation services.

((Training process here does not a specific regulation. Some training also come up, but they run into problems and canceled. In fact, we need to show them that how well the standard documentation can improve their outcomes.)) (Head of Emergency Department with 5 years' work experience)

Another interviewer said:

((The requirements of our knowledge are that what the nurse can write and what cannot be documented. In fact, they have to be taught what to write without problems, in this regard the workshops is not functional, and some of the workshops that were canceled, which we learn more here from the experience we try our best to not repeat our mistakes again)) (A nurse in an emergency department with 11 years of work experience)

Based on the experience of nurses, the skills of nurses are formed gradually and over time and on the basis of learning from other experienced colleagues and sometimes trial and error. According to participants, a graduate must have attained acceptable professional skills during academic education, but for many reasons this evolutionary process has been transferred to the workplace and is completed during work experience.

All nursing services, including the care documentation category, are conducted in accordance with international standards, but the real barrier is the lack of a comprehensive indicator for this high-profile task.

A participant said:

((Nursing, like physicians, needs to be Retraining. Like them, they should be planned for us and set up specific programs based on the need for them. In these condition, we can hope to improve documentation. (A nurse of emergency department with 8 years of work experience)

((One of the guys said that the sentence I wrote took a big burden out of the nurse's shoulders, the nurse could have been accused without writing that sentence; this kind of thing is necessary; but unfortunately, the nurses do not know exactly what to do, and this leads to many problems)). (A nurse of emergency department with 15 years of work experience)

Based on the experience of nurses, nurses' ability in reporting has not grown, and the in-service training program has not been organized and continued to achieve this goal.

((We did not have much experience first. We recognized the dos and don'ts gradually with the experienced we gained. I remember one night, a sick person came because of abdominal pain, the doctor prescribed painkiller, then they diagnosed that the patient had a trauma, but the doctor did not understand; the patient died after 5 or 6 hours, and this was not reported in any report. This was an experience that from that time on, we must carefully listen to the patient and take a detailed biography)). (A nurse of emergency department with 5 years of work experience) 
((The reports are in bad hand writing without correct reporting. when you check, write the date and time please; just a check and a signature. the nurses have been trained at the beginning how to document, when they start and then learn, the result is that they learn how to work at the end of the course, when they want to leave.)) (A nurse of emergency department with 13 years of work experience)

\section{JOB BURNOUT}

Job burnout refers to a state of physical, emotional or mental exhaustion, which is mainly a result of long-term stress or disappointment." Job burnout is classified in two categories: job stress and work pressure.

Based on experience of participants, one of the main factors preventing the standard documentation of nursing care is the job stress arising from work in the emergency department:

((The most common problem is when the patient is consulted and the patient is going to be transferred to the care unit, but he denies, for example, three physicians visited him/her and 20 medications are prescribed, along with 5 hour orders; for example, the patient came at 8 am and stayed until 12 at night, well, he/she different medications, our colleagues and I were so stressful that the patient was ignored.)) (A nurse of emergency department with 5 years of work experience)

((At 10 o'clock, an hour medication must have been injected, but the nurse in charge was so busy and forgot the injection. It means that stress is the only factor, high stress leads to negligence, it also happens in uncrowded shifts, but it is rare)). (A nurse of emergency department with 6 years of work experience)

Based on the experiences of nurses, work pressure is another effective factor in the failure to realize a significant improvement in the documentation of nursing care services due to the crowd of clients and, consequently, the occurrence of errors in the recording of important patient care records.

((They came to say that the night shift nurse had not told the doctor that the blood pressure of the patient was 7 . The nurse says that he told the doctors, but the doctor did not write the order. What do you think was the answer? They said that you should go to the doctor many times to get an order. It cannot be always done. One of the problems we have is that we cannot do this with the crowd of patients in the emergency room. It happened that we had 70 patients in the emergency room that is 70 records, leave alone the outpatient and stitches, 70 is a very high number. That is, the shift was so hard for the nurses)). (A nurse of emergency department with 11 years of work experience)

(I think the patient's condition should be written in detail, if the patient has a problem, it should be noted, yes, now if we have time. But many times there is no time at all in the emergency room, we have to ignore a lot of things)). (A nurse of emergency department with 8 years of work experience)

\section{PERCEIVED CONTROL}

Control and supervision of the assessment of decisions and programs were created since their implementation and the necessary measures to prevent deviation of operations from program objectives and correction of possible deviations(9). Perceived control is classified into two categories of planned control and effective control.

Participants believed that positive efforts and lack of efforts to improve the documentation in this collection were not seen due to the lack of monitoring and the lack of targeted control in this regard. A participant has said:

((For proper documentation, if we ignored something, I remembered to write it later. In these sort of thing, if there is no punishable aspect, for example, even reprimand, we accept it, and as a result, we work better. In general, I say that monitoring is poor)). (A nurse of emergency department with 5 years of work experience)

Another interviewee said:

((In the past, in emergency department, my manager examined sixty cases, for example, somebody wrote the consultation sheet, he didn't write the time and date; the doctor copied them, and show them to the one who checked; he said I would do nothing this time. I just reminded you, but the next time I'll ...It was very effective, but the problem is its discontinuation)). (A nurse of emergency department with 15 years of work experience)

Participants' experiences indicate that control is partly available in the unit, but it is worth noting that this control has not had a significant impact on documentation improvement.

( $($ s strongly believe that it is not effective without punishment; we will not understand without an objective case. During these years that we have been in the emergency department, we have always told our colleagues that they make mistakes, but they did not listen and the colleagues in charge did not take real actions)). (Head of Emergency Department with 5 years of work experience) 
(( 5 to 6 people should write a report on the sheet, reports must be compared to each other not to say that Mrs. ... did the reporting bad, this is not done now; I have not seen any head-nurse checking the reports, they take a look perfunctorily; how can this make documentation better!)) (A nurse with 15 years of experience)

Logical documentation is the actual, accurate, complete and timely recording of nursing practices (10). Intraorganizational coordination has focused on two areas of improvement of health information system and documentation time management.

\section{INTRA-ORGANIZATIONAL COORDINATION}

Intra-organizational coordination was classified in two categories of improvement of health information system and documentation time management. The health information system in this hospital is a replica of the software designed in the center of the country, and it seems that contributors need it to be native for better and faster use.

A participant said in this regard that:

(For example, we were told to record a graph separately, for example, radiographs of the arm and ... it is timeconsuming. The health information system has no benefit for us and we are writing the report. This will make me to spend the time of documentation on the system, we write correctly, but in the system, we may mark incorrectly. This will be a wrong cycle for the patient. It may make lead to a mistake. It must be mixed. We write in the graphs and CT scans separately)). (Responsible for the shift, a nurse with 10 years of work experience)

(It's not just only the physics that is recorded, but, for example, I give drugs to the patient; is it recorded in the HIS or not, there was a leaflet in which it was clear that these medications were given to the patient; and any medication given to the patient was recorded there, but now you have to access the computer. Without a computer, there is no access to the file. One of the advantages is that the paperwork has been reduced, but it is hard to check the file, to check a file item by item, to see if the file is requested by the hospital due to financial issues and to see if the hospital is not losing something, the patient is ok, but now the hospital is losing financially)). (Responsible for the accreditation of the health department)

One of the best ways to make use of the valuable time is to use it consciously, permanently and to manage it. In nursing, time is of particular importance and, given the principle of time, we will spend more time with the patient.

In this regard, a participant said:

((Reporting is hard, it means that sometimes it is very hard to write things, the nurses cannot write, because it is timeconsuming, we do not have time, we have many things to do, sometimes a patient comes, you do your work for 2 hours, you see that the patient is still on the station and you are still reporting)). (A nurse of emergency department with 8 years of work experience)

(The discussion in documentation is that why I do not observe these? Well, for example, it's hard to write. Why? Because I have too little time and I cannot write correctly. For example, we were told to record the graphs separately. For example, the radiography of the arm and ... it takes a lot of time.)) (A nurse of emergency department with 12 years of work experience)

\section{LEGAL BARRIERS OF DOCUMENTATION}

The experiences of participants indicate that nursing documentation does not document the rules, and this is one of the important issues that distorts nursing care and is effective in increasing the number of cases in the legal authorities.

(I remember a doctor wrote to inject methadone, then the medical jurisprudence told: why did you prescribe methadone for this patient? I told it was ordered by the doctor. He said you should not write whatever the doctor said, you should write down what the patient was complaining about. Have a pain in the stomach or the leg? You should mention in the report that you injected due to a headache; the doctor was punished in his place, but you should also comply. Well, maybe some guys do not know.)) (A nurse of emergency department with 5 years of work experience)

((Patient may came to the emergency room at 1:30 or 2:00 midnight. The patient was transferred to the room 4 to one of the beds. No one visited her and he became better. Unfortunately, our colleagues did not insist on writing a file for the patient. There were no names and specifications of this patient. It was also a problem with me that I didn't check the patients one by one in the morning, I only received the files and wrote but did not go to the room)). (A nurse of emergency department with 7 years of work experience) 
The experiences of participants in the emergency department indicate that the documentation contained in patientrelated documents does not comply with the rules of the nursing organization's documentation, and this is one of the important issues that has undermined nursing care which increases the number of cases in the legal references.

(The patient said that he has shortness of breath, we called the laboratory, they knew what they did, and we didn't record in the file, because the patient was ok and returned to the normal condition. At that time, my experience was less, but experience comes over time, we will do it again because it makes problem for us. Sometimes it write, even when something happens to the patient, because it may be useful to defend yourself, someday.)) (A nurse of emergency department with 11 years of work experience)

((The most powerful preventive force is the law, because that document or file is the only thing that can defend you. We had patient in Tehran with a fracture in the Fibula, he had an accident, and he came to the emergency room. He had a surgery. He went home then. They complained about a problem in his leg. We wrote this report correctly and we had control of it first. We wrote in the files that the patient's leg is impaired. That made me acquitted in this fight)). (A nurse of emergency department with 8 years of work experience)

\section{DISCUSSION}

The findings of this study were based on the experiences of nurses about the documentation of nursing services including competency of documentation categories, jobs burnout, perceived control, intra-organizational coordination, and legal barrier to documentation.

Nurses' experiences indicated that nurses' learning is based on experience, trial and error. They believed that academic education was not effective in their ability to perform documentation tasks, and it is necessary to review theoretical and practical topics in this regard. According to the participants, this process requires an infrastructural change. On the other hand, training programs for employees in an organization can also eliminate the need for a skilled workforce in the future and provide guarantees for solving employee problems. Job burnout is another most important factor of defect in the documentation of nursing services. The following measures are recommended in reducing the burnout of nursing staff: increasing the desirable number of nurses, increasing the recruitment rate, and reducing the recruitment time (11). In the scenarios of increasing the number of hospital beds and the rate of recruitment, which reflects the current conditions governing the employment and recruitment of nurses, the number of nurses is less than the actual need for these people, and the ratio of the number of nurses to the number of hospital beds is always less than 1.8 (12).

One of the points that contributors to this study have mentioned as the effective factor in failing to document nursing services is the emphasis on systematic, targeted and continuous control. According to contributors, control is not the reward and punishment system in a targeted and organized research environment, and it is the act of mitigating the motivation of nurses to improve documentation. Certainly, one of the tasks of executive managers at different levels and chief executives is to monitor and control the performance and in-organizational processes. The prominent importance of documentation and its impact on the quality of nursing care determine the role of monitoring this task. Nurses produce $50 \%$ of the care information, and are an important factor in the ongoing relationship between the care team members; this transition is related to clinical planning and decision-making in the area of care continuity.

Continuous control of these documents is realized in identifying the weaknesses and improving the nursing process in the form of nursing services documentation audit(13). Monitoring means visiting and checking with creating balance to keep things going, and preventing errors that lead to high costs(14). This is while, the effectiveness of the activities is largely dependent on the quality of monitoring carried out on those activities; on the other hand, undesired monitoring practices can lead to a decrease in the quality of activities.

Intra-organizational coordination was another important point that was mentioned by the interviewees. In this regard, the coordination between the manpower involved in the documentation of nursing care is a key point. Based on the experiences of nurses in the emergency department, there is no proper coordination between the members of the treatment team, especially between the emergency doctor and the nurses. This coordination is in line with the planning and establishment of the specialized committee. Insufficient motivation, inadequate in-service training, failure academic in education, and overcrowded patients in three working shifts and work pressure add problems. Assiri et al. (2016) pointed out in their findings that leadership and coordination style can play an important role in promoting the organizational commitment of nurses working in emergency care units (15).

The health information system is an appropriate tool for timely and targeted decision making(16). This system helps administrators of the institute by providing financial, administrative and clinical information by classifying and storing 
data (17). Participants believe that this system has been drawn from the capital, and it is not indigenous to this center, it has many problems and the purpose of the design of this system has not been achieved.

Legal barrier to documentation is a case that has been described as a barrier to the documentation of nursing care. In this regard, documentation is not recorded based on the patient, nurses believe that the documentation provided is not sufficiently based on the interaction with the patient and his relatives.

Ki Yung noted in his review that $83.7 \%$ of nurses are not aware of health rules that comply with Korean laws (17). Special attention of nursing managers and planners to this issue is necessary in planning of continuing education in order to take the necessary measures to improve the knowledge and attitude of nurses in relation to nursing rules and regulations.

\section{STUDY LIMITATIONS}

The limitations of this study can also be the existence of inherent errors and inevitable in the method of collecting the data of this study, as well as the limitations of this study, the multiplicity of stages of work, and the need for energy and time spent, which is specific to qualitative research.

\section{CONCLUSION}

In this study, 599 primary codes were extracted and the main themes Documentation competency, Job burnout, Perceived control, Intra-organizational coordination, Legal barrier extracted.

\section{ACKNOWLEDGMENTS}

This article is a part of the Ph.D. Nursing Thesis with the support of Mashhad University of Medical Sciences under the code 940864, and hereby, we appreciate all those who helped the researchers during the research.

\section{REFERENCES}

1. Wang N, Hailey D, Yu P. Quality of nursing documentation and approaches to its evaluation: a mixed-method systematic review. J Adv Nurs. 2011;67(9):1858-75. https://doi.org/10.1111/j.1365-2648.2011.05634.x PMid:21466578

2. Soto CM KK, Simon SR. Quality and correlates of medical record documentation in the ambulatory care setting 2002. BMC Health Serv Res 2002 Dec 10;2(1):22. https://doi.org/10.1186/1472-6963-2-22 PMid:12473161 PMCid:PMC140026

3. Stewart K, Doody O, Bailey M, Moran S. Improving the quality of nursing documentation in a palliative care setting: a quality improvement initiative. International journal of palliative nursing. 2017;23(12):577-85. https://doi.org/10.12968/ijpn.2017.23.12.577

4. Lee TT. Nurses' perceptions of their documentation experiences in a computerized nursing care planning system. Journal of Clinical Nursing. 2006;15(11):1376-82. https://doi.org/10.1111/j.1365-2702.2006.01480.x PMid:17038098

5. Vabo G, Slettebo A, Fossum M. Nursing Documentation: An Evaluation of an Action Research Project. Stud Health Technol Inform. 2016;225:842-3. PMid:27332370

6. Ofi BaS, O. Nursing Documentation: Experience of the Use of the Nursing Process Model in Selected Hospitals in Ibadan, Oyo State, Nigeria. Int J Nurs Pract. 2012;18:354-62. https://doi.org/10.1111/j.1440-172X.2012.02044.x PMid:22845635

7. Wang N, Yu P, Hailey D. The quality of paper-based versus electronic nursing care plan in Australian aged care homes: A documentation audit study. International Journal of Medical Informatics. 2015;84(8):561-9. https://doi.org/10.1016/j.ijmedinf.2015.04.004 PMid:26004340

8. Houghton C, Casey D, Shaw D, Murphy K. Rigour in qualitative case-study research. Nurse Res. 2013;20(4):12-7. https://doi.org/10.7748/nr2013.03.20.4.12.e326 PMid:23520707

9. Wang Q. The Discussion about Nursing Quality Management in Emergency Department. Journal of Nursing. 2015;4(1):19-22. https://doi.org/10.18686/jn.v4i1.6

10. Blair W, Smith B. Nursing documentation: Frameworks and barriers. Contemp Nurse. 2012;41(2):160-8. https://doi.org/10.5172/conu.2012.41.2.160 PMid:22800381 
11. Zhou F HY, Guo H, Liu H. Attitude, Knowledge, and Practice on Evidence-Based Nursing among Registered Nurses in Traditional Chinese Medicine Hospitals: A Multiple Center Cross-Sectional Survey in China. . J Evid Based Complementary Altern Med. 2016. https://doi.org/10.1155/2016/5478086 PMid:27528882 PMCid:PMC4978845

12. Taheri N, Barzabad PA, Yazdanpanah A. Comparative study of nursing group personnel number to active bed of hospitals affiliated to yasuj medical sciences university with existing standards and factors effective on it in 2015. Int J Clin and Biomed Res 2016;2(4):17-23.

13. Maia B, Barros A, Barros Barbosa A, da Silva P, Nauside M, Gomes Castelo Branco LM, et al. technical and scientific compilation about audit and quality management: an integrative review. Journal of Nursing UFPE/Revista de Enfermagem UFPE. 2017;3. https://doi.org/10.5205/1981-8963-v11i3a13993p1489-1494-2017

14. Pittman P, Bass E, Hargraves J, Herrera C, Thompson P. The future of nursing: Monitoring the progress of recommended change in hospitals, nurse-led clinics, and home health and hospice agencies. J Nurs Adm. 2015;45(2):93-9. https://doi.org/10.1097/NNA.0000000000000167 PMid:25581003

15. Asiri SA RW, Al-Surimi K, Da'ar OO, Ahmed A. The association of leadership styles and empowerment with nurses' organizational commitment in an acute health care setting: a cross-sectional study. BMC nursing. 2016;15(38). https://doi.org/10.1186/s12912-016-0161-7

16. Weeger A, Haase M, editors. How Social Capital between Medical and IT Professionals Shapes the Outcomes of Health Information System Implementation Endeavours. ECIS;2016. PMid:26940035

17. Kim K-K, Kim I-S, Lee W-H. Perception of legal liability by registered nurses in Korea. Nurse Educ Today. 2007;27(6):617-26. https://doi.org/10.1016/j.nedt.2006.09.010

$\diamond \diamond \diamond \diamond \diamond \diamond \diamond$

http://www.ejgm.co.uk 